\title{
Energy storage: The route to liberation from the fossil fuel economy? ${ }^{\text {is }}$
}

\author{
Peter J. Hall *
}

\section{Background: The inevitability of increasing global energy demands and possible energy sources}

The combined drivers of an ageing energy infrastructure, rising fossil fuel prices and the demand for low-carbon energy mean that the provision of energy in 2050 is likely to be fundamentally different from that of today. Although exact predictions are a near impossibility, there are a number of developments that can act as technology signposts. Most analysts predict an increase in energy demand up to and beyond 2030. Fig. 1 shows the Energy Information Administration 2007 (US-DOE, 2007) predictions for energy growth up to 2030, which shows an overall increase of $57 \%$ in energy use over the period 2004-2030. These predictions are representative of other agency findings. These figures should not, of course, be accepted uncritically and, in particular, two issues arise:

- Can or should societal requirements for energy be artificially (in other words politically) limited?

- Are energy requirements likely to rise or fall given higher energy efficiency?

There is currently a lively debate of these important questions. Pertinent to the first question is the observation by the EIA that energy requirements will rise by $24 \%$ for OECD countries by 2030 , but by a factor of $95 \%$ for non-OECD countries. It will prove politically much more difficult to control growth in industrially developing countries. Energy-efficiency measures may also control energy growth, but there is considerable evidence that they have limited value, whether as a natural restriction or as a political tool to control energy utilisation, because of what is called the 'rebound effect' (Dimitropoulos, 2007; Jin, 2007).

Therefore, the assumptions made in this discussion are that it will prove impossible to curb or limit energy requirements in a competitive market, and that those energy requirements are likely to increase monotonically until at least 2050.

The next obvious question concerns the origin of current and additional energy supplies up to 2030. Again, an analysis of the EIA figures is revealing. In 2004, 'non-carbon' sources of energy (nuclear and renewables) accounted for $14 \%$ of total global energy production, the balance being from the basket of fossil fuels (coal, oil and gas). The EIA predictions show a corresponding contribution of $13 \%$ in 2030 , identical in statistical terms.

Again, these figures should not be accepted without criticism or analysis. The most obvious relates to the availability and price of oil and its impact on the overall energy market. There are many arguments in energy regarding the so-called 'time invariant constants'; for example, that there always seems to be 40 years of oil available or that nuclear fusion is always 40 years away. Such arguments are historicist in character (Popper, 1993) and there is little doubt that although there is still a substantial amount of oil globally, it is increasingly difficult to exploit. There will be substantial progress in nuclear fusion engineering, and fusion will become a reality from 2050 onwards.

Partly because of increasing demand from industrialising countries, the price of oil is expected to increase geometrically rather than arithmetically, as demand continuously outstrips supply. But there is no doubt that fossil fuels, especially coal, can provide the additional energy. The International Energy Agency figures (IEA, 2006) show a $54 \%$ and $209 \%$ increase in the use of oil and coal, respectively, over the period 2004-2030. Additionally, technologies such as direct coal liquefaction and Fischer-Tropsch (FT) technologies can provide liquid fuels and have been industrially demonstrated. Nuclear energy carries its own problems not only in terms of waste disposal and management but also in terms of fuel supply. 


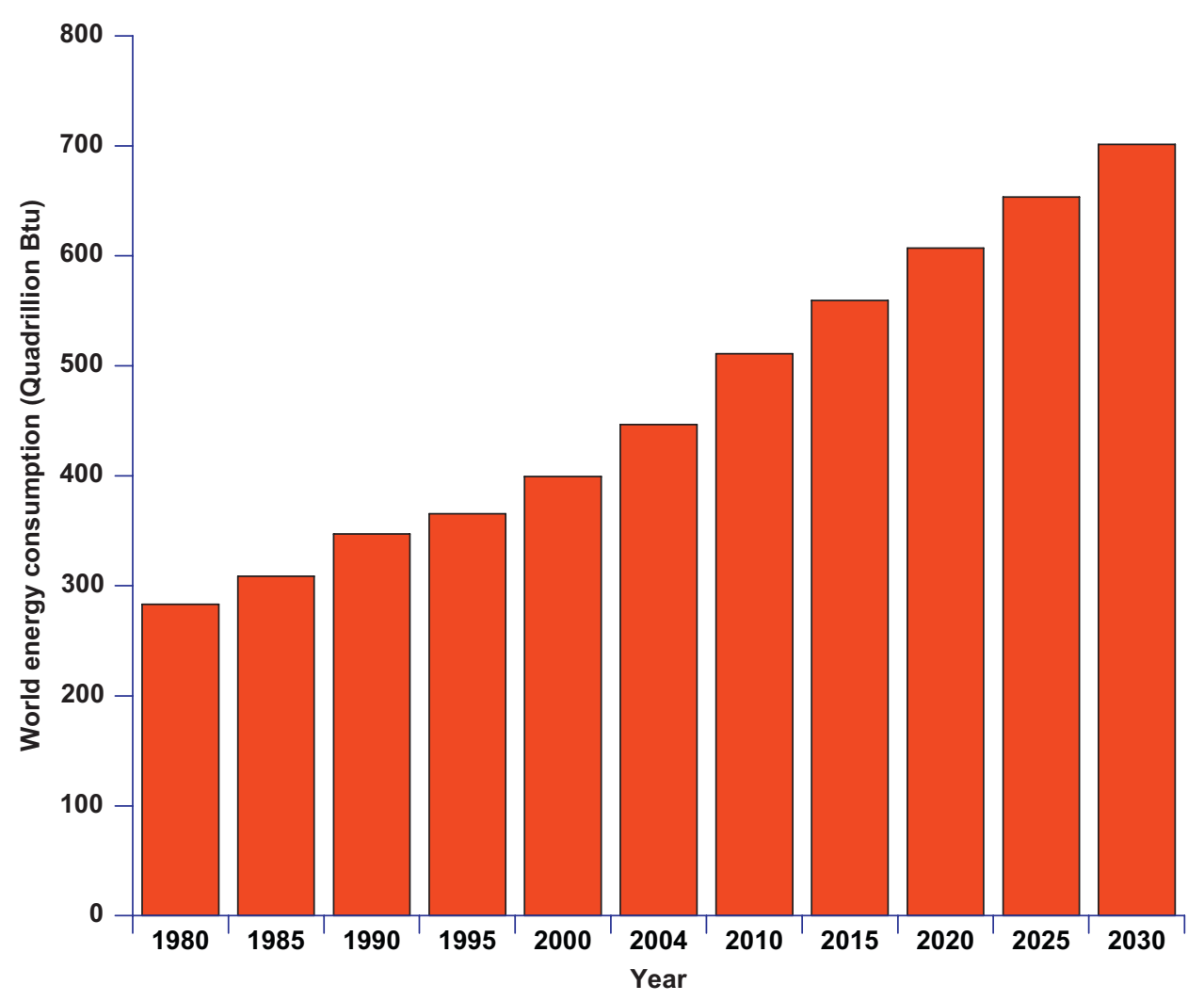

Fig. 1. The US-DOE values and predictions for energy utilisation in the period 1980-2030.

This brief analysis shows a picture of monotonically increasing energy demand up to at least 2050 with little impact from energy conservation and a continued reliance on fossil fuels. The consequences of this will be a continuous increase in the atmospheric concentration of greenhouse gases, with their effects on global climate. The questions to be considered here are whether it is possible to deploy new technologies to favour the growth of renewable energy over fossil fuel consumption, which sort of technologies are available and how they should be deployed. Before these are considered, a more detailed picture of how energy is consumed in industrial countries and the corresponding technological influences needs to be given.

\section{Trends in energy utilisation until 2050}

In this section, the UK situation will be used as a typical example of energy utilisation and energy trends for an OECD country (UK, 2007). To a good approximation, energy usage is evenly divided between homes, industry and transport and, notwithstanding the decline of heavy industry in the UK, this division is not likely to change to any great extent.

For domestic applications, centralised gas and electricity suppliers dominate the energy market. Major divergent trends are likely to be increasing energy efficiency coupled with a rise in so-called 'micro' domestic energy production.

The question to be considered is whether the majority of dwellings will be completely independent of a national electrical grid and can effectively become electrically self-generating entities based on renewable technologies. Technologically, this is entirely possible, given local microgeneration coupled with the delivery of a transportable fuel such as hydrogen or methanol used to produce electricity through a fuel cell. This is a highly efficient system, since even low-temperature fuel cells provide heat as well as power (Srinivasan, 2006). Photovoltaic (PV) systems, although reducing in price exponentially, are always inherently limited by their power density, the maximum amount of energy that can be generated per square meter of panel. This is currently limited to approximately $1 \mathrm{~kW} / \mathrm{m}^{2}$, while the payback time for capital investment in PV is persistently over 3 years. However, the development of lower cost, organically based excitonic solar photon collecting devices may overcome this limitation (Peter, 2007).

However, electrical generation is only one aspect of domestic energy requirements, space heating being the other major requirement. Currently, this is supplied by electricity or gas in a completely wasteful process that converts valuable high-grade heat or energy to essentially irrecoverable low-grade heat. (The terms low-grade and high-grade heat are conventional terms used by Chemical Engineers, broadly to denote whether a heat source is capable of raising steam.) However, desiccants and other materials may offer a technological solution (Kundhair and Farid, 2004).

In many respects, energy for transport offers the greatest challenge and is a battleground of competing technologies:

- conventional liquid fossil fuels with improved efficiency through hybridisation,

- fuel cells and hydrogen (Satyapal et al., 2007),

- electrochemical (battery and supercapacitor),

- bio-derived liquid fuels.

The range of applications is equally wide, from small twowheeled vehicles to cars, busses, trucks, and marine and air transport. Progress is being made in all of these and many have been demonstrated. Among others, the CUTE programme in the EU has demonstrated the feasibility of a purely hydrogen-driven 
public transport system, and Tesla Motors is demonstrating the feasibility of purely battery-driven personal transport.

Industrially, the major demand will be for continuous power on a fairly large scale. In the manufacturing sector, the chemical industry currently uses $21 \%$ of industrial energy in the UK, and $85 \%$ of this energy comes from fossil fuel sources. For a variety of reasons there is a tendency to transfer energy-intensive bulk chemical processes outside the UK, which means a general increase in the importance of pharmaceuticals in this sector. This may mean a slight reduction in energy utilisation within this sector.

Probably the greatest challenge to the requirements for industry will come from the requirement for power quality good enough for digital applications from the service sector (Seoto et al., 1995). The proportion of power for these applications is rising annually and there is ample evidence that this will continue. In fact, power quality issues are already becoming a major productivity issue and these problems will only intensify if there is an increased reliance on renewable energy sources (Barker, 2007).

\section{Energy sources in $\mathbf{2 0 5 0}$}

Considering that there are a number of coal-fired power stations under construction or awaiting approval, and that the lifetime of these new plants will be of the order of 40 years, it is inevitable that coal will provide a significant part of UK energy production in 2050. This is true for all OECD countries. However, there is enough momentum behind the development of carbon capture and storage (CCS) technologies to suggest that they will enable electricity to be generated from coal with a very much reduced carbon footprint. Similarly, the consensus in most OECD countries is that new nuclear technologies will provide a significant proportion of future energy supplies. These represent the traditional means of electrical supply. In summary, the predominance of traditional large-scale power production is guaranteed until 2050. The question is how great the proportion will be.

Oil, gas and coal pose more complex problems. The response to sudden increases in oil prices has traditionally been an increase in automotive efficiency. The reduction of average car size in the 1970s and the current development of diesel/battery hybrids can be seen in this light. Consequently, despite price fluctuations the reserve to production ratio has maintained an almost constant level of 40 years since 1985 (Bentley, 2002). The period until 2050 may feature exploitation of possible reserves under the Argentine/ Falklands continental shelf together with increasing domination of the oil market by Russia. The economic viability of coal conversion technologies such as direct liquefaction and FT processing could well imply that liquid hydrocarbons are the transport fuel of choice well beyond 2050. It is to be noted that South Africa already produces $15 \%$ of its diesel from FT (Schulz, 1999) and that China is running large pilot plant facilities for both direct coal liquefaction and FT.

Future use of liquid hydrocarbons must balance the increasing pressure on oil supplies from the rapidly developing Indian and Chinese economies and the sheer expense of further subcontinental shelf oil development. From an environmental point of view, it is a near impossibility to efficiently capture $\mathrm{CO}_{2}$ from literally tens of millions of cars and other vehicles.

Probably the biggest divergence from the energy status quo will be the introduction of smaller units producing energy intermittently or randomly. Such sources are predominantly powered by winds, tides, waves or the sun, and are already an established, although small, part of the energy infrastructure. They are very attractive from an electrical production point of view because once the capital costs have been recovered, the running costs are much less than for coal combustion and there is no need for complex negotiations to obtain fossil fuel supplies on an increasingly competitive international market. Renewables are also almost carbon-zero. Bio-derived liquid fuels such as biodiesel are gaining prominence within the UK but are mainly seasonal in nature, although wood-derived fuels mitigate this problem to some extent. It is certain that bioconversion will only ever supply a small fraction of the transport needs of the UK without largescale imports of supplies.

\section{The promotion of renewable energy towards $\mathbf{2 0 5 0}$}

To summarise the above, there are no technological reasons why fossil fuels cannot provide all society's energy needs by 2050 , through conventional power generation coupled with the production of liquid fuels. Nuclear energy will undoubtedly play an important part in future energy supply but, unless there are some fundamental changes, renewables are likely to be restricted to a contribution of less than $15 \%$, for reasons to be discussed below.

The key problem lies in the intermittent nature of renewables and the way in which they are connected to large electrical grids. The first factor means that energy is produced when it is not needed and vice versa. In more technical language, renewables are not load-following. The second can give rise to grid instabilities in the form of low-frequency oscillations (Rogers, 1999). The solution to both problems lies in energy storage, which is central to the wide deployment of renewables. Energy storage is also central to the use of renewables in the transport sector, which is vital in the quest for a reduction in the use of fossil fuels.

There are a wide variety of technologies for energy storage, which are appropriate to different situations (Price, 2005). Following the discussion above, the domestic, transport and industrial sectors will be considered in turn.

Energy storage for domestic applications should be technologically simple and transparent and cover two essential needs, electrical generation and space heating. Domestic electricity can be generated from two principal sources, wind and solar. Of course, surplus electricity can be exported to the electrical grid, but a far simpler solution is to store it in batteries. The ideal solution lies in the form of lithium ion batteries because of their high energy density in space and weight terms, their lack of memory effect, their low loss rate and their overall efficiency in the cycle of storing and releasing power. Mass production and the development of nano-structured materials offer considerable scope for cost reduction.

The main competitor for battery storage is the use of hydrogen as an energy vector. Hydrogen could be generated from a domestic electrolyser, stored under pressure and converted back to electricity through a fuel cell. While entirely technically feasible, the whole process is far less efficient than the lithium ion battery route (Srinivasan, 2006), far more costly, and poses the safety questions of handling an odourless and highly explosive gas. It is probably not feasible to odorise hydrogen in the same way as domestic natural gas because of the deleterious effects of the odorising agents (mercaptans) on fuel cell electrodes. Fuel cell electrodes contain platinum group metals that are easily deactivated by a variety of agents, including sulphur-containing compounds.

The other domestic requirement of space heating could in principle be met from stored electricity, but given the cost of lithium ion batteries this is probably not a viable option. A more promising method is the use of desiccants and other energy storage chemicals, which release heat on contact with moisture. This promises to be a safe and cost-effective solution for the longterm storage of energy for producing low-grade heat. Desiccants 
can be dried using solar energy (in a much more efficient process than capturing photons in PV devices) or waste heat from power stations (Kundhair and Farid, 2004).

Whatever the case for microgeneration, a large portion of domestic energy requirements is likely to be delivered through an electrical grid. The problems of running grids on renewables will be considered shortly in the paragraphs relating to industrial power requirements.

The complexity of technologies competing to replace oil in the transport sector has already been noted. There is no question that in terms of convenience and energy density, oil is the ideal energy source. However, as has been noted above, hydrogen and batteries are already making minor but important inroads into the transport sector (Lokey, 2007). The main impact of hydrogen as an energy vector is likely to be for transport. The question is whether it is possible to produce enough hydrogen for the energy needs of an industrial country and what problems need to be overcome.

On the plus side, hydrogen can be produced from virtually carbonless energy source including renewables (via water electrolysis), biomass (through gasification) and nuclear (via water electrolysis or thermochemical cycles). Hydrogen in most stored forms (solid, liquid or metal hydride) has an energy density large enough for most transport applications. Direct hydrogen fuel cells, although currently expensive, have been successfully demonstrated for over 40 years and are more efficient than Carnot cycle engines at low temperatures. Also, it should be noted that in a real sense we already have a hydrogen economy because without hydrogenation reactions, oil would be largely unusable. Hydrogen is already one of the most important chemical commodities, and is not known to be environmentally damaging.

However, hydrogen also has certain limitations. All fuels are dangerous, but hydrogen should be regarded as the most dangerous of all. It is colourless and odourless, and it is depressingly easy to engineer an air/hydrogen explosion (Zalosh et al., 1978). The consequences of dealing with it with anything but the utmost respect are generally fatal.

Economically, the main problem would be to convert an energy infrastructure that is used to handling liquid fuels to one that handles a gas. Even though the hydrogen storage medium may be, for example, a solid, stable metal hydride, hydrogen in its gaseous form must be produced in at least one stage in the conversion process. Also, the process of storing and releasing hydrogen via a fuel cell has a maximum thermodynamic efficiency of less than $50 \%$. For these reasons, it is highly unlikely that any of the six global trillion-dollar GDP countries could adopt a complete hydrogen economy. Iceland may be the only country where a hydrogen economy in this form may be feasible.

The main competitor to the hydrogen economy is regarded as the 'electron' economy, in which generated electricity is either used directly or stored electrochemically for further usage. Under this scenario, electricity can be generated centrally as well as locally but electrons are effectively the power source for the domestic, transport and industrial markets. The main weakness of this is the current state of battery technology in terms of energy density and the recharging times of secondary batteries. The main advantage is its relative efficiency. Since energy is always stored in the form of electrons, conversion efficiencies are always higher than for processes that involve chemical energy.

The most likely scenario is that future transport needs will be based on a hybridisation of hydrogen fuel cell and battery technologies in which the amount of hydrogen generated is minimised. Since a full-scale hydrogen infrastructure is economically unlikely, a growing portion of refuelling will occur domestically through small-scale electrolysers and direct battery charging. This will take advantage of any renewable energy that is generated domestically as well as renewable energy delivered through an electrical grid. Again, energy storage in the form of lithium ion batteries and hydrogen is central to these developments.

There is no conceivable scenario in which industry could generate all of its electrical needs from local renewable energy sources. It will be purchased from centralised generators as today, and the majority of energy will be generated from large-scale sources such as nuclear power plants or medium-sized sources such as wind farms and marine sources. Again, the key to increasing the proportion of energy from renewable sources is energy storage. This will allow a continuous output of electricity, or adequate supplies when they are needed the most. The gross inefficiency and cost of the hydrogen/fuel cell route have already been noted. It makes this technology an undesirable choice for grid energy storage. Battery technology may offer a solution, perhaps in the form of flow battery systems. However, these are associated with highly toxic or environmentally damaging chemicals and are not preferred. Alternative technologies such as flywheels may be deployed. In many respects this represents the greatest challenge to the development of energy storage technology.

The problems of grid connection instabilities in the form of low-frequency oscillations and the need for highly stable power supplies for digital applications have already been noted (Rogers, 1999). Again, energy storage represents the solution to these problems (Wang, 2000). Grid stabilities can be rectified by the application of supercapacitors and techniques such as superconducting magnetic energy storage.

\section{Renewable energy: A utopian future?}

To summarise the above: in 2050 it will be normal for people to take a greater personal responsibility for energy, generating it when necessary and purchasing it from a range of suppliers. This could involve self-generation using micro wind turbines and solar-powered fuel cells. Large corporations or farmer cooperatives could supply any additional energy in the form of liquid fuels to power fuel cells. This would apply to single-family homes or local communities. Personal transport would be integrated into this system by way of hydrogen powering automotive fuel cells and by the use of plug-in batteries. This means that most domestic and transport infrastructures will be fully integrated.

Public transport will require a separate infrastructure. Bus transportation, for example, is associated with fixed and (one hopes) predictable routes, so it is ideally suited to electrochemical power. There will be no need for a hydrogen infrastructure. There is also a technological fix for arguably the most problematic form of transport: aviation. There is no scientific reason why biodiesel cannot be upgraded to aviation turbine fuel. This is a logical use for bio-derived hydrocarbons since there is not nearly enough scope for the provision of general transportation from this source.

Industrial needs are a separate matter. There is little scope, for example, for the City of London to generate its own energy. It will continue to be purchased from central generating companies. The same will apply for the electronics and chemical sectors. The reason for this is the absolute need for clean and reliable power and the potential consequences of a loss of power. The energy sources for this will be coal with some CCS, renewables with energy storage and power.

Perhaps the most important role for organic fossil resources will be for the provision of speciality chemicals and polymers. This is a high-value sector with ample scope for development.

Perhaps the only feature that all energy forecasters will agree upon is that in 2050, energy will come from far more diverse and 
distributed sources, and on scales from domestic, local and regional renewable to national or international. To this will be added the complications of integration of transport into the hydrogen electron economy. This system cannot function without some form of massive energy reservoir, which, with the exception of fossil fuels, simply does not exist today. Energy storage must and will be ubiquitous. It will range from domestic energy storage to absorb electricity from PV panels or wind turbines to on-board automotive energy storage, through to devices large enough to store energy from individual wind turbines and devices for ensuring power quality. The main debating point is whether the storage will be in the form of hydrogen or electrons. The author argues that electron storage in the form of lithium-based batteries will win this Darwinian contest because of their superior overall efficiency, safety and cost. The economic problems of creating a completely new hydrogen infrastructure may prove to be prohibitive. Hydrogen may play an important role when produced from local electrolysers and biomass gasification and will have a pivotal role in the transport market.

In conjunction with energy storage technologies, renewables offer the prospect of cheap and sustainable energy. In many ways, renewables can do for energy what microchip-driven computers have done for information, and what genetic manipulation will do for medicine. Renewable energy offers the benefits of widespread choice and personal responsibility, and the hope that human endeavours will no longer be limited by the availability of energy.

The much quoted words of Saudi Arabia's former oil minister Sheikh Zaki Yamani, that the stone age did not end due to a lack of stones, may well prove prophetic over the next 40 years as oil and other fossil fuels play an ever diminishing role in our societies, politics and wars.

\section{References}

Barker, S., 2007. The hidden cost. Computer and Control Engineering 18, 10-11. Bentley, R.W., 2002. Global oil and gas depletion: an overview. Energy Policy 30 , 189-205.

Dimitropoulos, J., 2007. Energy production and the rebound effect: an overview of the state of knowledge. Energy Policy 35, 6354-6363.

IEA, 2006. World Energy Outlook 2006. International Energy Agency.

Jin, S.H., 2007. The effectiveness of energy efficiency improvement in a developing country: rebound effect of residential electricity use in South Korea. Energy Policy 35, 5622-5629.

Kundhair, A.M., Farid, M.M., 2004. A review on energy conservation in building applications with energy storage by latent heat using phase change materials. Energy Conservation and Management 45, 263-275.

Lokey, E., 2007. A critical review of the Energy Policy Act of 2005s treatment of hydrogen. International Journal of Hydrogen Energy 32, 1673-1679.

Peter, L.M., 2007. Dye-sensitized nanocrystalline solar cells. Physical Chemistry Chemical Physics 9, 2630-2642.

Popper, K., 1993. The Poverty of Historicism. Routledge, UK.

Price, A., 2005. Electrical energy storage-a review of technology options. Proceedings of ICE 158, 52-58.

Rogers, G., 1999. Power System Oscillations. Kluwer, The Netherlands.

Satyapal, S., Petrovic, J., Read, C., et al., 2007. The US Department of Energy's National Hydrogen Storage Project: progress towards meeting hydrogenpowered vehicle requirements. Catalysis Today 120 (3-4), 246-256.

Schulz, H., 1999. Short history and present trends of Fischer-Tropsch synthesis. Applied Catalysis A: General 186, 3-12.

Seoto, D., He, S.D., Woo, C.K., 1995. Pricing electric harmonics. Energy 20, 617-621.

Srinivasan, S., 2006. Fuel Cells: From Fundamentals to Applications. Springer, New York. UK, 2007. Digest of United Kingdom Energy Statistics 2007. URN No: 07/87.

US-DOE, 2007. United States Department of Energy, Energy Information Authority Report 'International Energy Outlook 2007'. Report number DOE/EIA0484(2007), July 2007.

Wang, H.F., 2000. A unified model for the analysis of FACTS devices in damping power system oscillations. III. Unified power flow controller. IEEE Transactions on Power Delivery 15, 978-983.

Zalosh, R.G., Short, T.P., Marlin, P.G., Coughlin, D.A., 1978. Comparative analysis of hydrogen fire and explosion incidents: OSTI ID: 6868081 Report number, COO-4442-3 DOE Contract number EE-77-C-02-4442. 